\title{
Making Sense of Coproduction: What Is It Good For?
}

Gabrielle Roesch-McNally and Holly R. Prendeville, Northwest Climate Hub ${ }^{1}$

\section{Why is coproduction important?}

Coproduction is the "process of producing usable, or actionable science through collaboration between scientists and those who use science" (Meadow et al. 2016). Lack of coproduction with end users is arguably one of the reasons why much scientific information and resulting decision support systems are not very usable (Wall et al. 2016). Increasingly, public agencies and academic institutions are emphasizing the importance of coproduction of scientific knowledge and decision support systems in order to develop more engagement between the scientific community and key stakeholder groups. In particular, coproduction can be helpful in addressing complex social and ecological problems that have no simple answers and require engagement across multiple stakeholder groups to resolve. Coproduction has

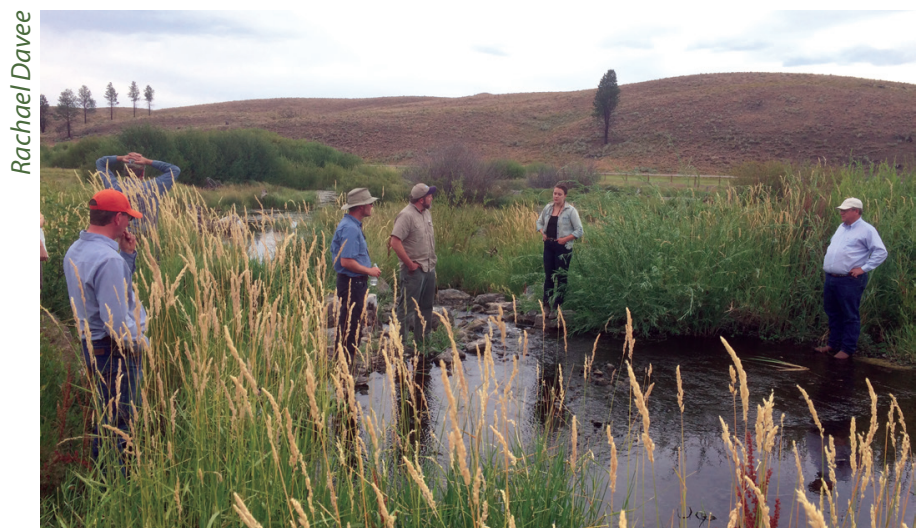

Land managers discuss stream restoration with Forest Service and Oregon State University scientists. been embraced as a way for the scientific community to develop actionable scientific information that will assist end users in solving real-world problems. Coproduction is ultimately a negotiated and iterative engagement with stakeholders, which develops over time (Bartels et al. 2013, Dilling and Lemos 2011). This kind of engagement is increasingly necessary, particularly in the context of growing politicization of science and concerns about whose knowledge counts. Coproduction can be an effective way to build trust and coproduce knowledge systems that build on and integrate local and traditional knowledge. Employing coproduction strategies may enable the development of more relevant and useful information and decision support tools that address stakeholder challenges at relevant scales.

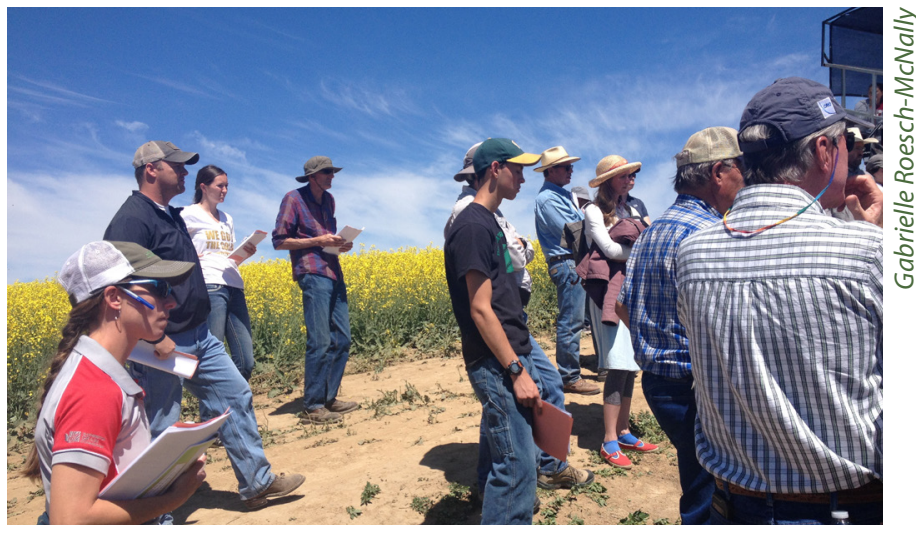

Farmers attend field day with Agricultural Research Station scientists in the Inland Northwest.

${ }^{1}$ Gabrielle Roesch-McNally (groeschmcnally@fs.fed.us) is a Climate Hub Fellow; Holly R. Prendeville (hollyrprendeville@fs.fed.us) is a Climate Hub Coordinator; U.S. Department of Agriculture, Forest Service, Pacific Northwest Research Station, 3200 SW Jefferson Way, Corvallis, OR 97331 


\section{Coproduction as a process of engagement}

Coproduction is one way to approach stakeholder engagement. Note the process of engagement is as important as the end result (Cash et al. 2006), owing to enhanced collaboration and transfer of knowledge among all parties involved. Coproduction begins with setting the agenda, including determining what questions are being asked and how the research process should be designed (Wall et al. 2016). Although coproduction design includes many aspects, we have synthesized sevenkey elements (developed from Bartels et al. 2013, Beier et al. 2016, Meadow et al. 2015, Reed et al. 2014) to include in its application (Wall et al. 2016):

Purposeful recruitment of a broad set of stakeholders including key stakeholder groups.

\section{Ways of engaging}

Efforts to collaborate with stakeholders, including coproduction processes, have been developed to counter the notion that experts should be isolated from decisions makers and that scientific information should be delivered in a top-down way (Cash et al. 2006). Usable science requires an iterative approach which relies on collaborative relationships between scientists and decision makers and can be facilitated through different forms of engagement (Dilling and Lemos 2011). Truly collaborative research is where "scientists and local experts not only exchange relevant information but
1. Regular and repeated interaction with stakeholders during the project, including agenda setting research, analysis, tool development, outreach, and evaluation phases.

2. An emphasis on tangible, timely results that address concerns of collaborating stakeholders.

3. Long-term engagement (relationship building takes time and trust).

4. Opportunities for reflection and evaluation of the process and the tangible work.

5. Developing usable science that makes science understandable and available to relevant stakeholders.

6. Research that integrates interdisciplinary perspectives.

jointly generate (new) knowledge on the basis of their scientific as well as local expertise (joint research)" (Wiek 2007). To use coproduction methods to create useful scientific information, including decision support systems, it is helpful to think about what coproduction is and what it is not.

Engagement of stakeholders exists along a continuum (fig. 1), with different levels of stakeholder engagement ranging from no engagement (where only scientists engage other scientists, usually within their discipline) to collegial (where stakeholders are empowered with
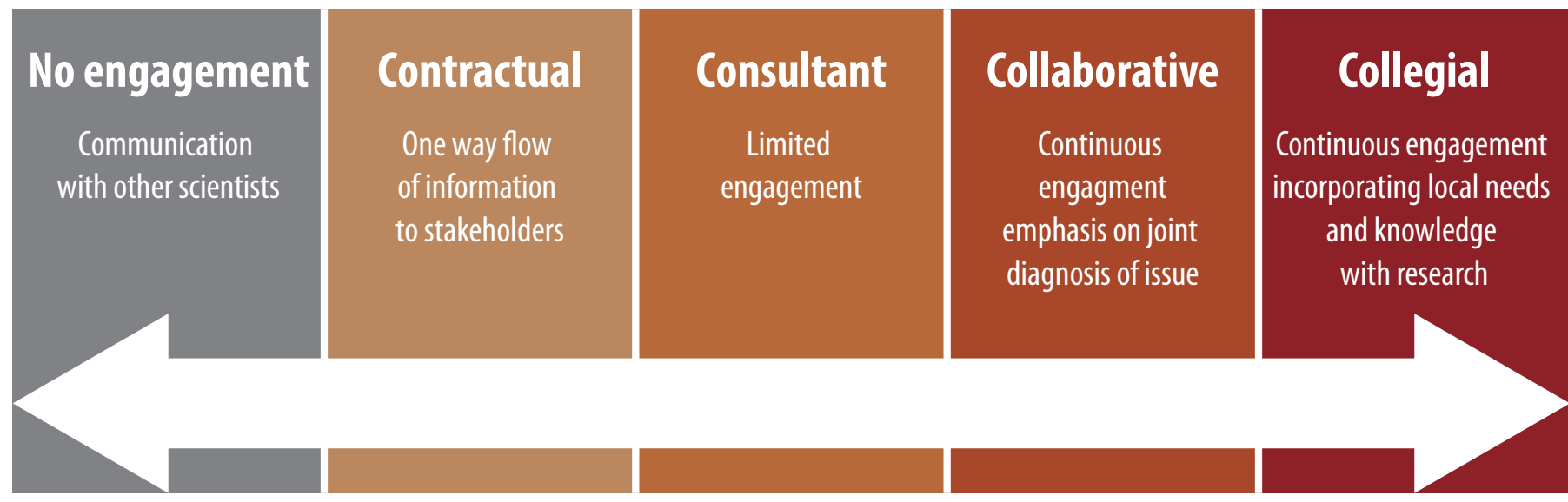

Figure 1-Continuum of engagement, adapted from Meadow et al. (2015). 
tools that help them to conduct research or pursue development goals), which is aligned with coproduction. Different levels of engagement (Meadow et al. 2016) are explained in detail below:

No engagement: Scientists are focused on communicating with other scientists. Sharing of scientific information happens in peer-review journals and at academic conferences. Other stakeholders are only minimally involved, if at all.

Contractual: Scientists share information in a unidirectional way, often limited to testing or verifying technology. This mode might engage stakeholders to test and give input on decision support tools or other applications, often late in the design and implementation phase.

Consultant: Scientists generally lead research design with stakeholder engagement at specific stages but not necessarily ongoing. These interactions might be planned phases of a research design where stakeholders are consulted on various aspects of an issue; often a third party is used to represent the interests of stake-

\section{Challenges with coproduction}

"Coproduction is expensive, time-consuming, difficult, and ambitious, and it will sometimes fall short of achieving actionable science, especially in the initial attempts" (Beier et al. 2016). While coproduction efforts are laudable and engagement of stakeholders is encouraged, coproduction is not a panacea. Coproduction requires the development of trust that is built over time (Wall et al. 2016), and because building relationships takes more time, this might reduce productivity, at least in academic terms (Coppock 2016). Additionally, because coproduction is a process where outputs and outcomes of a given project are dependent on collaborative design, it may be difficult to convince grantors to fund intangible processes versus specific products outlined at the outset of a particular project (Coppock et al. 2016). Therefore, greater efforts will be needed to holders, sometimes in the form of a social scientist communicating with an interdisciplinary team.

Collaborative: Scientists and stakeholders learn together in a continuous relationship that is a partnership, with emphasis on joint diagnosis of a problem, and including agreement about desired products or educational needs. Often stakeholders are trained in a mode of scientific research and may collect data as found in citizen science programs.

Collegial: Scientists work with stakeholders to build linkages between formal research that is stakeholder driven and local knowledge, which includes training stakeholders in the scientific process. This effort acknowledges the importance of multiple evidence-based approaches to research, which "proposes parallels where indigenous, local, and scientific knowledge systems are viewed to generate different manifestations of valid and useful knowledge" (Tengö et al. 2014) and integrates these systems in ways that can empower stakeholders to design and conduct research or develop their own decision support systems.

shift expectations with regards to process versus products in order to gain greater support for coproduction as a strategy for engaging stakeholders.

Despite the many challenges, coproduction may be increasingly needed as a tool to engage stakeholders in the process of knowledge creation in ways that are both iterative and collaborative, particularly in an era where science is contested terrain and whereby divisions among scientists, researchers, and the broader public seem more distinct than ever. Therefore coproduction will be a critical approach to ensuring actionable science that serves the interests of diverse communities, which can help solve complex social and ecological problems, such as climate change and other social-ecological problems. 


\section{NORTHWEST $\frac{\mathrm{HUB}}{4}$}

\section{References}

Bartels, W.L.; Furman, C.A.; Diehl, D.C.; Royce, F.S.; Dourte, D.R.; Ortiz, B.V.; Jones, J.W. 2013. Warming up to climate change: a participatory approach to engaging with agricultural stakeholders in the Southeast US. Regional Environmental Change. 13(1): 45-55.

Beier, P.; Hansen, L.J.; Helbrecht, L.; Behar, D. 2016. A how-to guide for coproduction of actionable science. Conservation Letters. 10(3): 288-296.

Cash, D.W.; Borck, J.C.; Patt, A. 2006. Countering the loading-dock approach to linking science and decision making comparative analysis of El Niño/Southern Oscillation (ENSO) forecasting systems. Science, Technology and Human Values. 31(4): 465-494.

Coppock, D.L. 2016. Cast off the shackles of academia! Use participatory approaches to tackle real-world problems with underserved populations. Rangelands. 38(1): 5-13.

Dilling, L.; Lemos, M.C. 2011. Creating usable science: opportunities and constraints for climate knowledge use and their implications for science policy. Global Environmental Change. 21(2): 680-689.
Meadow, A.M.; Ferguson, D.B.; Guido, Z.; Horangic, A.; Owen, G.; Wall, T. 2015. Moving toward the deliberate coproduction of climate science knowledge. Weather, Climate, and Society. 7(2): 179-191.

Reed, M.S.; Stringer, L.C.; Fazey, I.; Evely, A.C.; Kruijsen, J.H.J. 2014. Five principles for the practice of knowledge exchange in environmental management. Journal of Environmental Management.146: 337-345.

Tengö, M.; Brondizio, E.S.; Elmqvist, T.; Malmer, P.; Spierenburg, M. 2014. Connecting diverse knowledge systems for enhanced ecosystem governance: the multiple evidence base approach. Ambio. 43(5): 579-591.

Wall, T.U.; Meadow, A.M.; Horganic, A. 2016. Developing evaluation indicators to improve the process of co-producing usable climate science. Weather, Climate, and Society. 9. doi: 10.1175/wcas-d-16-0008.1.

Wiek, A. 2007. Challenges of transdisciplinary research as interactive knowledge generation-experiences from transdisciplinary case study research. GAIA-Ecological Perspectives for Science and Society. 16(1): 52-57. 